Ther mal hydraul i c char act eri st i cs of super conducting coil cool ed by subcool ed He I

\begin{tabular}{|l|l|}
\hline $\begin{array}{l}\text { jour nal or } \\
\text { publ i cat } i \text { on } \mathrm{t} \text { i t l e }\end{array}$ & I EEE Tr ansact i ons on Appl i ed Super conduct i vi t y \\
\hline vol une & Vol . 14 \\
\hline number & I ssue 2 \\
\hline page $r$ ange & pp. 1439-1442 \\
\hline year & 2004 06-01 \\
\hline URL & ht t p: //hdl . handl e. net /10655/2237 \\
\hline
\end{tabular}




\title{
Thermal Hydraulic Characteristics of Superconducting Coil Cooled by Subcooled He I
}

\author{
S. Hamaguchi, S. Imagawa, N. Yanagi, Y. Hishinuma, T. Mito, K. Takahata, H. Chikaraishi, H. Tamura, A. Iwamoto, \\ S. Yamada, and A. Nishimura
}

\begin{abstract}
Superconducting magnets of helical coils for the Large Helical Device (LHD) have been operated by saturated helium at $4.4 \mathrm{~K}$ and plasma experiments have been carried out at less than 3 T successfully. Now, it is considered that the subcooled He I will be used to improve the operating condition of the superconducting magnets of the LHD helical coils. To use subcooled He I as a coolant for the superconducting magnets of the LHD helical coils, we need to investigate the cooling characteristics and the stability of a superconducting coil in the subcooled $\mathrm{He}$ I. So, an R \& D coil, wound with superconductors for the LHD helical coils, was cooled with the subcooled and saturated helium, then stability tests of the coil were carried out. Subcooled and saturated He I was supplied from the bottom of the coil and flowed out to a bath of current leads at the pressure of $120 \mathrm{kPa}$. The temperature of the supplied He I was 3.1, 3.5 (subcooled $\mathrm{He}$ I) and 4.4 K (saturated He I) at the outlet of the heat exchanger. In the present experiment, the helium temperature distribution in the cooling channels of the $R \& D$ coil was measured under steady state conditions and the transient helium temperature change in the channels was observed in stability tests. This paper discusses the thermal hydraulic characteristics of the $R \& D$ coil from these results.
\end{abstract}

Index Terms-Stability test, subcooled He I, superconducting coil, thermal characteristics.

\section{INTRODUCTION}

S UPERCONDUCTING magnets of the helical coils for the Large Helical Device (LHD) have been operated by saturated helium at the temperature of $4.4 \mathrm{~K}$ and pressure of 120 $\mathrm{kPa}$. Up to now, plasma experiments have been carried out at a magnetic field lower than $3 \mathrm{~T}$ successfully [1]. However, the operating field has not reached the design value of $3 \mathrm{~T}$. So, it is considered that the superconducting magnets of the LHD helical coils will be cooled with the subcooled He I to achieve the nominal field of $3 \mathrm{~T}$ [2]. To use subcooled He I as a coolant for the superconducting magnets of the LHD helical coils, the cooling characteristics and stability of superconducting magnets in subcooled He I have been studied.

An $R$ \& D coil was fabricated with superconductors for the LHD helical coils. This coil was cooled with subcooled He I, then stability tests were carried out [3]-[5]. In the present experiments, the temperature distribution of the subcooled $\mathrm{He} I$

Manuscript received October 21, 2003.

The authors are with the National Institute for Fusion Science, 322-6 Oroshi, Toki, Gifu 509-5292, Japan (e-mail: hamaguchi@LHD.nifs.ac.jp).

Digital Object Identifier 10.1109/TASC.2004.830642
TABLE I

MAIN PARAMETER OF THE R \& D COIL

\begin{tabular}{ll}
\hline \hline \multicolumn{1}{c}{ Item } & \multicolumn{1}{c}{ Design Values } \\
\hline Superconductor & $\begin{array}{l}\text { NbTi/Cu conductors with pure } \\
\text { aluminum as a stabilizer } \\
\text { (for helical coils of LHD) }\end{array}$ \\
Maximum magnetic field & $6.9 \mathrm{~T}$ at $13.0 \mathrm{kA}$ \\
Number of turns & 24 (tum) $\times 12$ (layer) \\
Inductance & $29 \mathrm{mH}$ \\
Gap between turns & $2 \mathrm{~mm}$ \\
Gap between layers & $3.5 \mathrm{~mm}$ \\
Percentage of cooled area & $67 \%$ at inner layer \\
Outer radius of R \& D coil & $395 \mathrm{~mm}$ \\
Inner radius of R \& D coil & $200 \mathrm{~mm}$ \\
Cooling channels & $7.5 \mathrm{~mm}{ }^{2} \times 24$ (inner) \\
& $25 \mathrm{~mm}{ }^{2}$ (side) \\
Inlet of coolant & $300 \mathrm{~mm}$ (outer) \\
Outlet of coolant & $250 \mathrm{~mm} \times 20 \mathrm{~mm}$ (bottom) \\
\hline \hline
\end{tabular}

in the cooling channels of the R \& D coil was measured under steady state condition and the transient temperature change of the subcooled $\mathrm{He} I$ was observed during stability tests. The transient thermal behavior of the subcooled helium in the cooling channels of the R \& D coil was also calculated when a normal zone propagation was initiated. In the present paper, the thermal hydraulic characteristics of the R \& D coil are discussed from experimental and numerical results.

\section{EXPERIMENT}

The R \& D coil design was based on the LHD helical coils, using the same superconductors. The superconductors had the cross-sectional area of $18 \mathrm{~mm} \times 12.5 \mathrm{~mm}$. The design magnetic field applied to the superconductors of the $R \& D$ coil was $6.9 \mathrm{~T}$ at $13.0 \mathrm{kA}$, which is the same as the maximum field of the LHD helical coils. The winding consisted of 24 turns and 12 layers. The cooling channels were formed by the superconductors and FRP spacers, with the gaps being $2 \mathrm{~mm}$ (turn) and $3.5 \mathrm{~mm}$ (layer) as in the LHD helical coils. The ratio of the area exposed to subcooled He I to the area covered with FRP spacers was $67 \%$ at the innermost layer, which is the same ratio as the LHD helical coils. The inner radius of the $R \& D$ coil was $200 \mathrm{~mm}$ and the outer radius was $395 \mathrm{~mm}$. The main parameters of the R \& D coil are listed in Table I. 


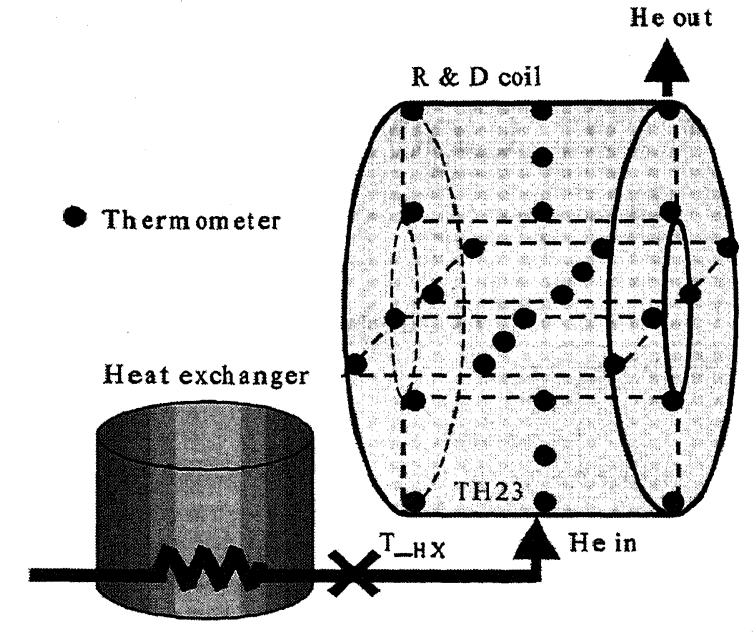

Fig. 1. Schematic view of the test facility for superconducting coil cooled with subcooled $\mathrm{He}$ I. Subcooled He I was generated at the outlet of the heat exchanger and was supplied from the bottom of the R \& D coil. The 28 solid circles show the position of thermometers in the coil.

TABLE II

MAIN PARAMETERS OF EXPERIMENTAL CONDITIONS

\begin{tabular}{ll}
\hline \hline \multicolumn{1}{c}{ Quantity } & Operating Values \\
\hline Temperature $\left(\mathrm{T}_{\mathrm{HX}}\right)$ & $3.1,3.5,(4.4) \mathrm{K}$ \\
Pressure (current lead bath) & $120 \mathrm{kPa}$ \\
Mass flow rate & $5-10 \mathrm{~g} / \mathrm{s}$ \\
Maximum operating current & $12.4 \mathrm{kA}$ \\
Height of heat pulse & $30-100 \mathrm{~W}$ \\
Duration of heat pulse & $20 \mathrm{~ms}$ \\
\hline \hline
\end{tabular}

Cernox thermometers were bonded with epoxy to the surface of the FRP spacers in the $R$ \& D coil to measure the temperature of subcooled $\mathrm{He} \mathrm{I}$ in the cooling channels. The position of the thermometers is shown in Fig. 1. Subcooled He I was generated at the heat exchanger, where the enthalpy of liquid helium at $0.12 \mathrm{MPa}$ was transferred to a saturated helium bath pumped by cold compressors. $T_{\mathrm{HX}}$ was located at the outlet of the heat exchanger. The subcooled $\mathrm{He} I$ as a coolant was supplied from the bottom of the R \& D coil. TH23 was situated at the coolant inlet to the R \& D coil. The coolant flow went from the top end of the R \& D coil to a bath of current leads. A heater was inserted between a spacer and a superconductor at the bottom of the center turn of the innermost layer.

The experimental conditions are listed in Table II. The R \& D coil was immersed with flow in the subcooled $\mathrm{He} I$ at $0.12 \mathrm{MPa}$. The supplied helium temperature was 3.1 or $3.5 \mathrm{~K}$ at the outlet of the heat exchanger in the present experiments. The pressure of the bath of the current leads was set to $120 \mathrm{kPa}$. The mass flow rate of the subcooled He I was $5-10 \mathrm{~g} / \mathrm{s}$ throughout the present experiments. In the stability tests, heat input from the heater to the superconductors was $30-100 \mathrm{~W}$ for $20 \mathrm{~ms}$.

The steady state temperature distribution of the subcooled helium in the cooling channels of the R \& D coil was measured while the coil was cooled down. The transient helium temperature changes were also observed when normal zone propagations occurred with heat applied to the superconductor in the stability tests.

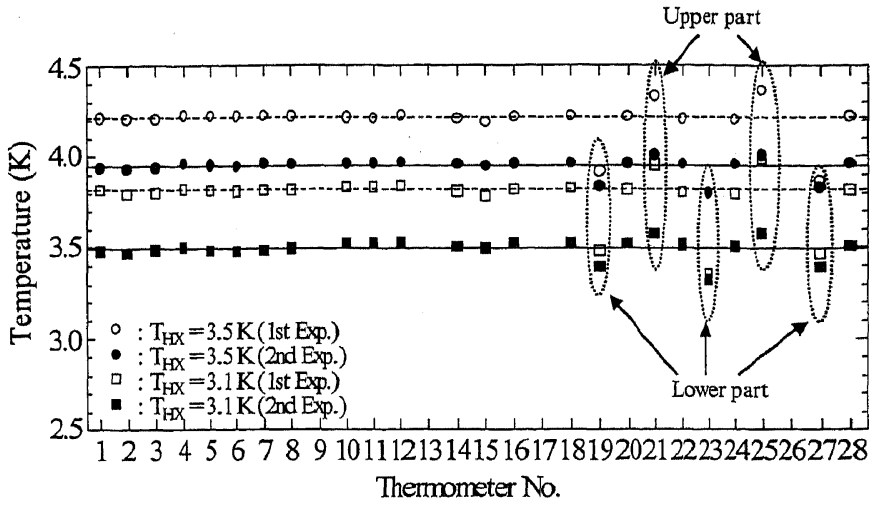

Fig. 2. Temperature distribution of subcooled He I in cooling channels of the R \& D coil under steady state condition. Open marks and dashed lines show results of 1st experiment in December 2002, while solid marks and solid lines report results of 2nd experiment in October 2003. TH19, TH23, and TH27 are located at the bottom of the coil, close to the inlet of subcooled He I. TH21 and TH25 are located at the top of the coil, close to the outlet of the coolant.

\section{RESULTS AND DISCUSSION}

\section{A. Steady State}

Fig. 2 shows the temperature distribution of the subcooled helium in the cooling channels of the $\mathrm{R} \& \mathrm{D}$ coil under the steady state. Open marks and dashed lines show results of the first experiment in December 2002, while solid marks and solid lines results of the second experiment in October 2003. TH19, TH23 and TH27 were located in the lower part of the coil, close to the inlet of the subcooled He I. TH21 and TH25 were situated in the upper part of the coil, close to the outlet of the coolant. In the first experiment, the temperature of the inlet of subcooled $\mathrm{He}$ I (TH23) was $3.35 \mathrm{~K}$ and the temperature in the R \& D coil was $3.8 \mathrm{~K}$ when the temperature of the outlet of the heat exchanger $\left(\mathrm{T}_{\mathrm{HX}}\right)$ was $3.1 \mathrm{~K}$. On the other hand, the temperature of TH23 was $3.8 \mathrm{~K}$ and the temperature in the coil was $4.2 \mathrm{~K}$ when the temperature of $T_{\mathrm{HX}}$ was $3.5 \mathrm{~K}$. In the second experiment, the temperature of $\mathrm{TH} 23$ was $3.3 \mathrm{~K}$ and the temperature in the coil was $3.5 \mathrm{~K}$ when the temperature of $\mathrm{T}_{\mathrm{HX}}$ was $3.1 \mathrm{~K}$, while the temperature of $\mathrm{TH} 23$ was $3.8 \mathrm{~K}$ and the temperature in the coil was $3.95 \mathrm{~K}$ when the temperature of $\mathrm{T}_{\mathrm{HX}}$ was $3.5 \mathrm{~K}$. The temperature in the coil was uniform except for TH19, TH23, TH27 (lower part) and TH21, TH25 (upper part) owing to very high heat conductivity of the superconductor, which utilized aluminum as a stabilizer. As a result, stable operation of the coil cooled with subcooled He I is expected because the degradation of the stability caused by the difference of the local temperature exist scarcely in the coil. However, the temperature in the upper part of the R \& D coil (TH21, TH25) was higher than that of the other points because of the arrangement of the cooling channels where the subcooled He I was stagnant.

The heat leak estimated from the increase of the helium temperature in the $R$ \& D coil was $20 \mathrm{~W}$ in the first experiment. After the test facility was warmed up at room temperature, a 4 $\mathrm{K}$ shield, which consisted of a copper plate covered with super insulation, was added in order to decrease the heat leak. The 4 Kshield was installed around the coil vessel and was attached on the bath of the current leads as a thermal anchor. Consequently, the helium temperature in the coil decreased by about $0.3 \mathrm{~K}$ and the estimated heat leak reduced to $7 \mathrm{~W}$. 


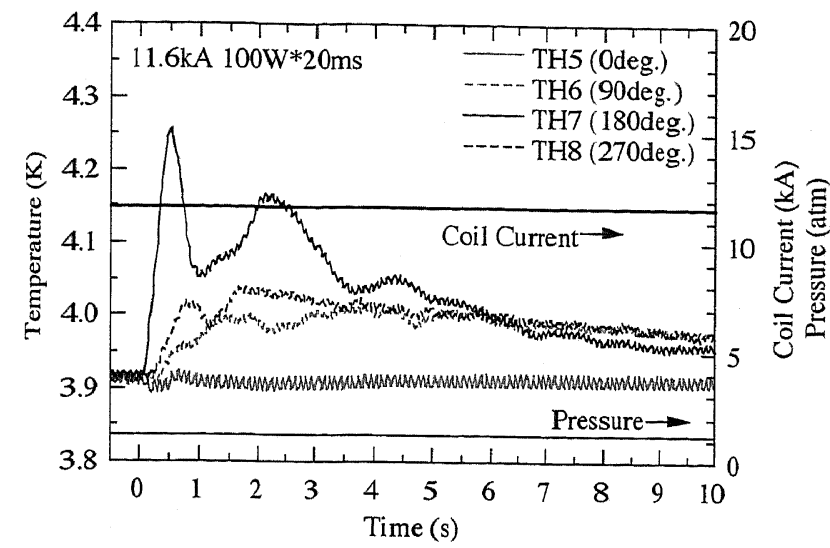

Fig. 3. Temperature profile of subcooled He I in channels of R \& D coil when heat of $100 \mathrm{~W}$ was applied to the superconductor during $20 \mathrm{~ms}$. The initial helium temperature was $3.9 \mathrm{~K}$ in the coil, the helium pressure was $120 \mathrm{kPa}$ and operating current was $11.6 \mathrm{kA}$. In this stability test, normal zone propagation occurred toward the downstream of the operating current. The pressure of the current lead bath was stable.

\section{B. Transient}

Fig. 3 shows the temperature change of the subcooled $\mathrm{He} \mathrm{I}$ in the $\mathrm{R} \& \mathrm{D}$ coil when the coil current was $11.6 \mathrm{kA}$ and the heat input applied from a heater to a superconductor was 100 $\mathrm{W}$ for $20 \mathrm{~ms}$ at $3.9 \mathrm{~K}$. At this time, the normal zone propagation occurred in the superconductor near the heater, the normal zone traveled downstream with the operating current, and the normal zone disappeared spontaneously. The helium temperature near the heater ( $\mathrm{TH} 7$ ) increased, then the helium temperature rose at the middle portion of the inner layer (TH6, TH8). After the normal zone disappeared, the helium temperature decreased gradually and it took $30 \mathrm{~s}$ to return to the initial temperature of $3.9 \mathrm{~K}$. But the temperature did not change at the top of the inner layer (TH5). Also, the pressure of the current lead bath and the temperature at the inlet of subcooled He I (TH23) did not change. It is implied that natural convection was induced due to the difference in density. In this case, the cooling system of the R \& D coil was stable.

To investigate the thermal hydraulic behavior of subcooled He I in cooling channels of the R \& D coil, a dynamic calculation was carried out under the conditions described in the previous paragraph, using the finite element method. In the present calculation, an analytical area was meshed on left half of the $r-\theta$ plane because of the symmetric configuration (see Fig. 4), with 10272 elements. Time step was set to $5 \mathrm{~ms}$. The initial helium temperature and pressure in the coil were $3.9 \mathrm{~K}$ and $120 \mathrm{kPa}$, respectively. At the inlet of the subcooled $\mathrm{He} \mathrm{I}$, the helium temperature was kept at $3.9 \mathrm{~K}$ and the mass flow rate of the helium was $8.5 \mathrm{~g} / \mathrm{s}$. After the heat of $100 \mathrm{~W}$ was applied to the heater surface during $20 \mathrm{~ms}$, the post heating of $192 \mathrm{~W}$ was added uniformly to the innermost layer for $400 \mathrm{~ms}$, simulating a Joule heating of the normal zone propagation.

Fig. 5 shows the transient helium temperature profile as a result of the calculation. The helium temperature near the heater (TH7) increased, then the helium temperature rose in the middle portion of the inner layer (TH6 or TH8), while the temperature did not change at the top of the inner layer (TH5) as in the experiment. After the post heating, the helium temperature recovered slowly to the initial temperature of $3.9 \mathrm{~K}$. In the recovery

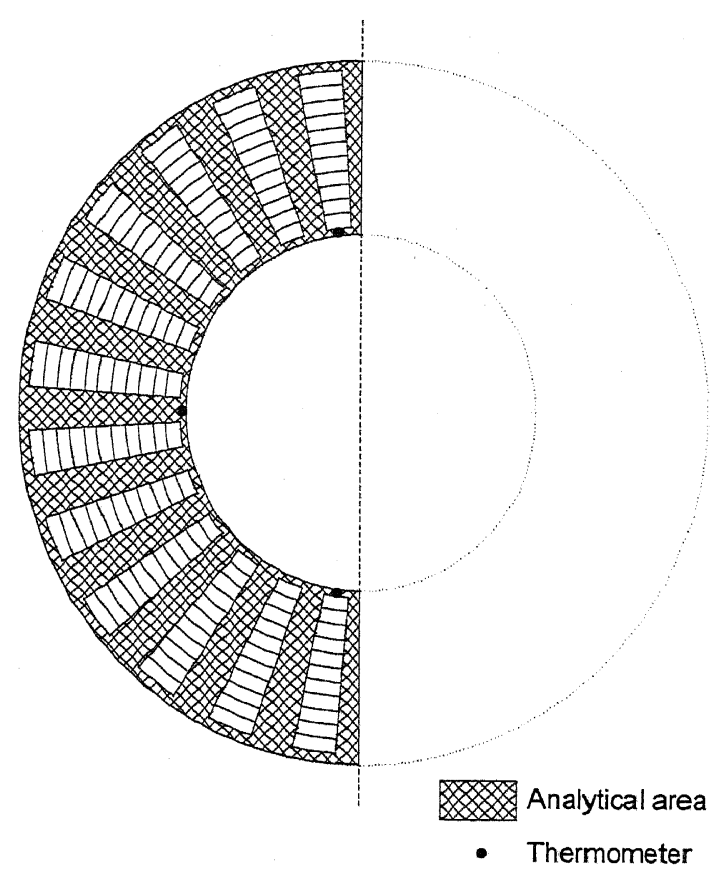

Fig. 4. Numerical model to investigate the thermal hydraulic behavior of subcooled $\mathrm{He} \mathrm{I}$ in the cooling channels of the $\mathrm{R} \& \mathrm{D}$ coil. The analytical area is left half of $r-\theta$ plane. Open rectangles represent FRP spacers, where the adiabatic condition is applied. Solid circles show the position of thermometers. A heater is located at the upper boundary of the lowest innermost spacer. The inlet of subcooled helium is set to outside of the lowest element, while the outlet of the coolant is set to outside of highest element. The present calculation was carried out, using a transient two dimensional finite element method.

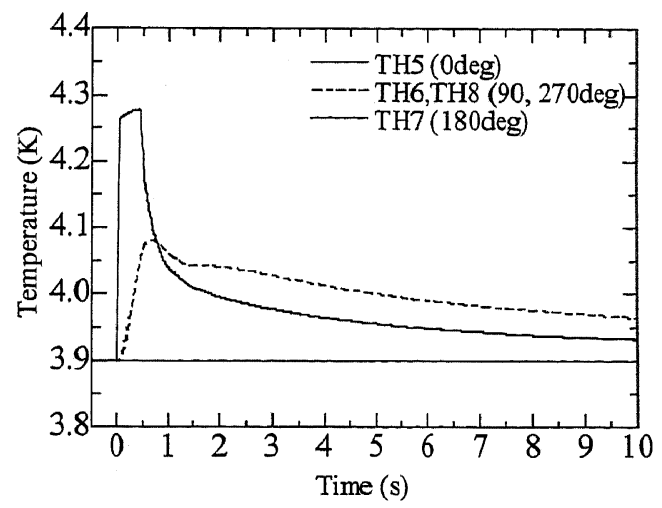

Fig. 5. Subcooled helium temperature profile as a numerical result. After the heat pulse was $100 \mathrm{~W} \times 20 \mathrm{~ms}$ as an input from heater, the heat of $192 \mathrm{~W}$ was applied during $400 \mathrm{~ms}$, based on the normal zone propagation. The initial temperature in the coil was $3.9 \mathrm{~K}$, while the pressure was $120 \mathrm{kPa}$.

process, the temperature of $\mathrm{TH} 7$ became lower than that of TH6 (or TH8) under the influence of the induced natural convection.

Fig. 6 displays the helium temperature change in the $\mathrm{R} \&$ $\mathrm{D}$ coil when the coil current was $12.2 \mathrm{kA}$ and the heat input applied from a heater to a superconductor was $42 \mathrm{~W}$ during $20 \mathrm{~ms}$ at $3.85 \mathrm{~K}$. In this case, the normal zone propagation, which started at the superconductor near the heater, spread toward both the downstream and upstream of the operating current, then the coil was discharged to protect itself. The helium temperature at the middle and lower part of the inner layer (TH6, TH7, TH8) became the saturated helium temperature of 4.4 $\mathrm{K}$, then the helium temperature abruptly increased in the discharging process. The helium temperature dropped to the 


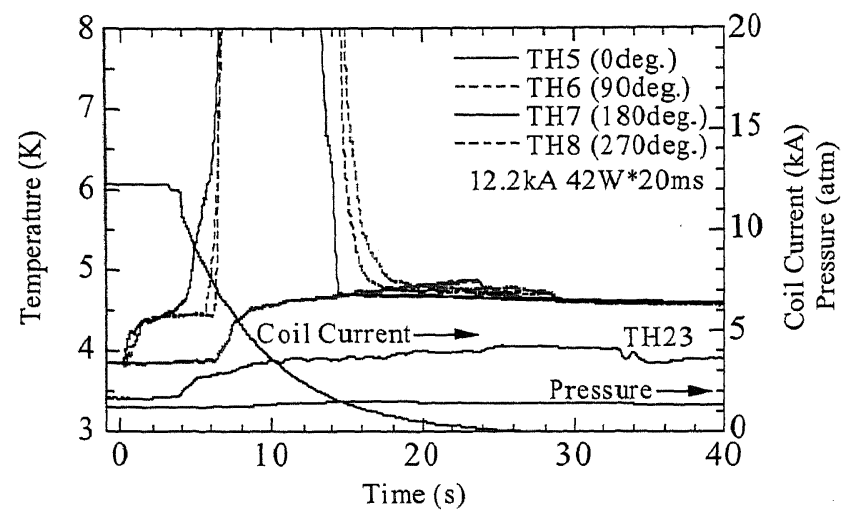

Fig. 6. Transient temperature change of subcooled He I in the channels of the $\mathrm{R} \& \mathrm{D}$ coil when operating current was $12.2 \mathrm{kA}$ and the heat of $42 \mathrm{~W}$ was applied to the superconductor during $20 \mathrm{~ms}$. The initial helium temperature was $3.85 \mathrm{~K}$ in the coil, while the helium pressure was $120 \mathrm{kPa}$. In this stability test, normal zone propagation occurred toward both the downstream and upstream of the operating current, then the coil was discharge quickly. The pressure of the current lead bath and the temperature of TH23 increased.

temperature at the saturated vapor pressure quickly when the coil current decreased. On the other hand, the helium temperature at the top of the inner layer (TH5) increased late and remained at the saturated helium temperature due to the change in pressure. Subsequently, the temperature in the coil took 30 minutes to return to the initial temperature of $3.85 \mathrm{~K}$. This will be discussed in the next section. The pressure of the current lead bath and the temperature at the inlet of subcooled He I (TH23) increased in contrast to the case of one-side normal zone propagation, because the discharging process was experienced in the case of both sides normal zone propagation. Consequently, although the cooling system of the R \& D coil became somewhat unstable in this case, the operation of the coil had been carried out safely.

\section{Recovery}

The heat, which was generated in the R \& D coil, was removed by the flow of subcooled helium. The mass flow rate of supplied subcooled He I was 5-10 g/s. In the previous stability test, it was $8.9 \mathrm{~g} / \mathrm{s}$. It was assumed that the difference of the enthalpy between supplied subcooled He I and the coolant at the outlet of the coil contributed only to the cooling of the coil. The amount of heat, which should be removed, was the increase of the enthalpy of both the superconductor and helium in the coil. Consequently, the estimated recovery time was $28 \mathrm{~min}$ utes, which was $93 \%$ of the experimental result, in the case of mass flow of $8.9 \mathrm{~g} / \mathrm{s}$. Since this estimation was in good agreement with the experimental result, the validity of this assumption was proved. The estimated time depended strongly upon the mass flow rate. The helium temperature will, therefore, return to the initial temperature faster if the mass flow rate can increase.

\section{CONCLUSION}

The R \& D coil, wound with superconductors for the LHD helical coils, was cooled with the subcooled He I and the stability tests of the coil were carried out. The helium temperature distribution in the cooling channels of the coil was measured under the steady state condition and transient helium temperature change was observed in the stability tests.

The temperature in the coil kept uniformly owing to very high heat conductivity of the superconductor with an aluminum stabilizer. As a result, stable operation of the coil cooled with subcooled $\mathrm{He} \mathrm{I}$ is expected because the degradation of the stability exist scarcely in the coil. In the case of one-side normal zone propagation, the helium temperature recovered slowly to the initial temperature of $3.9 \mathrm{~K}$ under the influence of the induced natural convection. When both sides normal zone propagation occurred, the temperature in the coil took 30 minutes to return to the initial temperature of $3.85 \mathrm{~K}$. According to the estimation, the recovery time depended strongly upon the mass flow rate.

\section{ACKNOWLEDGMENT}

The authors would like to thank Dr. K. Seo for his helpful suggestions. The authors also appreciate the help of Dr. R. Maekawa to review the paper.

\section{REFERENCES}

[1] A. Tiyoshi et al., "Design construction and the first plasma experiments in the Large Helical Device," Fusion Eng. Des., vol. 46, pp. 323-335, Nov. 1999.

[2] S. Imagawa et al., "Excitation properties and cryogenic stability of helical coils for the LHD," IEEE Trans. Appl. Supercond., vol. 11, no. 1, pp. 1889-1892, Mar. 2001.

[3] Y. Hishinuma et al., "Design and Operation of the Sub-Cooled R\&D System for the LHD Helical Coils," this conference.

[4] S. Imagawa et al., "Results of Stability Test in Subcooled Helium for the R\&D Coil of the LHD Helical Coil," this conference.

[5] N. Yanagi et al., "Asymmetrical Normal-Zone Propagation Observed in the Aluminum-Stabilized Superconductor for the LHD Helical Coils," this conference. 